\title{
Engaging Ranchers in Market-Based Approaches to Climate Change Mitigation: Opportunities, Challenges, and Policy Implications
}

\section{By Hannah Gosnell, Nicole Robinson-Maness, and Susan Charnley}

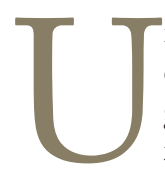

nsustainable rangeland management and land conversion are significant sources of greenhouse gas emissions and global warming; however, rangelands also can be managed to mitigate climate change by enhancing carbon uptake through increased plant production and biological sequestration. Given that rangelands comprise approximately 312 million ha (770 million acres) in the United States alone, ${ }^{1}$ and that, according to a 2000 USFS General Technical Report, there are opportunities to make distinct categorical rangeland condition improvements on approximately $90 \%$ of privately managed acres in the United States, ${ }^{2}$ management of these lands is a critical factor to be considered as policies regarding climate change mitigation are crafted.

One way to engage ranchers in climate change mitigation is to develop a carbon market that compensates them for managing their lands in ways that sequester carbon to offset the emission of greenhouse gases by others. Between 2008 and 2010, approximately 1,000 US ranchers participated in the US voluntary carbon market through the Chicago Climate Exchange (CCX). Drawing on results from interviews conducted in 2009 with 28 ranchers in Montana, Wyoming, Colorado, and New Mexico enrolled in the CCX program, we describe some of their experiences. Additional interviews with key informants, including aggregators, brokers, range scientists, and agency personnel, inform our discussion of challenges associated with including ranchers in carbon markets and issues that will need to be addressed to develop relevant policy.

\section{Ranchers and the US Voluntary Carbon Market} Currently within the United States, the mechanisms for buying and selling carbon offsets are strictly through the voluntary market. Until late 2010, the CCX was the only legally binding system for trading emission sources and offset projects. (The CCX announced in November 2010 that it would stop trading carbon credits due to inactivity in US carbon markets.) In addition to CCX transactions, many carbon credits (each representing the reduction of 1 metric ton of carbon dioxide emissions or equivalent) have been bought and sold directly as "over-the-counter" (OTC) transactions through private brokers.

Carbon credits sold on the CCX were "generic," because they could come from forestry, methane capture, renewable energy, or agriculture and rangeland soil carbon projects. Over the past few years, prices for these generic credits ranged from over $\$ 7.00 /$ ton in May 2008 down to $\$ 0.10 /$ ton in mid-2010. Prices for CCX rangeland credits sold OTC were generally higher, because they were traceable to a specific agricultural offset project.

Regardless of the mechanism for exchange, carbon credits generally are associated with some type of standard or protocol that verifies the amount of carbon sequestered by a given project. The CCX was the only emissions trading platform with a protocol for carbon offsets from rangelands in the United States. Led by a technical review team of soil scientists, the CCX developed their Rangeland Soil Carbon Offset protocol in 2007. Landowner participation in the program required a minimum 5-year "legally binding commitment to defined management practices which increase soil carbon stocks on rangelands." ${ }^{3} \mathrm{CCX}$ required that credits registered on the exchange be from projects generating more than $10,000 \mathrm{mtCO}_{2} \mathrm{e}^{\mathrm{i}}$ in emission reductions per year. As

' $\mathrm{mtCO}_{2}$ e stands for Metric Tons of Carbon Dioxide Equivalent. This is the standard measurement of the amount of $\mathrm{CO}_{2}$ emissions that are reduced or secluded from the environment. 
such, most landowners in the Midwest and West worked with an aggregator, allowing them to be part of a pool of carbon credits aggregated from multiple properties. These aggregators (e.g., North Dakota Farmers Union, National Carbon Offset Coalition) guided landowners through the process of engaging in the carbon market and charged a fee, usually a percentage of carbon credit sales.

The protocol used Land Resource Regions, defined by the National Cooperative Soil Survey, as a geographic basis for issuance rates for belowground carbon sequestration and outlined a list of eligible practices believed to increase carbon sequestration (e.g., prescribed grazing schedules, ensuring sustainable forage for livestock and wildlife, contingency management plan for drought conditions) that had to be documented in a range management plan. Practices had to be voluntary, and above and beyond "business-as-usual."

To enroll, projects had to be reviewed by a third party verified to ensure they met the eligibility criteria and that they "adopt[ed] and demonstrate[d] conformance with a formal grazing plan" which, at a minimum ... [met] or exceed[ed] the Natural Resource Conservation Service standard" for Best Management Practices. With aggregated pools, only a random sample of $10 \%$ of the ranches in the pool were selected for in-field verification, although all ranches over 30,000 acres had to be field-verified during the first year. A verification report was submitted to the CCX for approval and landowners had the option to register their credits for sale through the CCX, for which they were charged a \$0.15/ credit registration fee, or they could sell them OTC.

The first iterations of the protocol included several provisions designed to encourage ranchers to participate in the fledgling market, such as 1) the ability to "back date" acres, allowing landowners to receive additional credits for "precompliance" with the protocol as far back as 1 January 1999; and 2) the ability to enroll acres with "degraded status," which qualified for a higher carbon sequestration crediting rate. Both of these provisions were eliminated in 2009 , because they had served their purpose of attracting ranchers to the carbon market early on. Moreover, the degraded status option posed the risk of creating perverse incentives for ranchers to purposely degrade land and then enroll it under that status in order to qualify for higher payments.

\section{Challenges Associated With Including Ranchers in Carbon Markets}

Our research on ranchers' experiences with the US voluntary carbon market suggests that there are a number of major

\footnotetext{
"The CCX defines "business-as-usual" as current practice on US rangelands characterized in the USFS General Technical Report cited above (i.e., practices that lead to "consistent soil problems and depleted productivity"). Put differently, CCX has determined that "long-term sustainable management practices are not common practice" (CCX 2009, p. 14). ${ }^{3}$ This is the baseline against which additional carbon sequestration is measured.
}

\section{Additionality and Early Actors}

One of the basic principles the procedures and requirements for offset project initiation are designed to address is that of additionality. Carbon offset markets were developed to incentivize sequestration activities that would not have occurred in the absence of the market. Therefore, many offset programs apply additionality criteria to guarantee that projects actually represent new sequestration (or net emissions reductions). In some circumstances then, although landowners already might engage in land management practices that help sequester carbon, these might not necessarily qualify for carbon offset credits. Landowners who have been following sustainable management practices for reasons other than carbon sequestration commonly might have generated higher levels of carbon storage in their plants and soils than those who have not (i.e., their baseline is higher). These "early actors" present a unique challenge for offset programs because, although their management activities might provide the same level of carbon sequestration as projects initiated by other landowners, they might not necessarily reflect new and additional carbon storage that would not have occurred in the absence of the market. In general, carbon offset programs will require landowners to employ practices that are above and beyond "business-as-usual." Each offset program uses its own definition of "business-as-usual," so activities considered additional (and therefore eligible for offset crediting) in some standards might not be considered additional in others. $^{5}$

issues that make their inclusion in these markets challenging, namely the spatial and temporal complexities inherent in quantifying and verifying soil carbon sequestration to ensure additionality, and problems associated with engaging ranchers as market participants. These two sets of concerns can be thought of as a "precision vs. practicality" problem. Protocols must be rigorous enough to provide assurance to buyers and the public that there is some level of precision in the quality and quantity of carbon offsets being sold; but ranchers need to be able to participate without prohibitive transaction or transition costs. Buy-in from ranchers is necessary to make the market work; therefore understanding ranchers' perceptions, predilections, concerns, and goals is essential. Finding the right balance between precision and practicality will be a central challenge for policymakers seeking to inform future legislation and institutional design. Here we expand on three specific facets of this challenge that will need to be considered: 1) designing a credible protocol that allows for adequate quantification and verification; 2) determining how additionality will be defined and how ranchers already in compliance with a given protocol will be treated; and 3) developing effective strategies for engaging ranchers. 
The Credibility Problem: Quantification and

Verification

Efforts to develop protocols guiding the generation of rangeland soil carbon credits are in their infancy and in a state of flux, as evidenced by the rapid evolution of the CCX protocol since its inception, and the indecision regarding whether ranchers should be included in other carbon offset protocols, such as the Climate Action Reserve. Protocol developers are grappling with a number of issues associated with including ranchers in the voluntary market.

First, because soil carbon is difficult and expensive to quantify, it currently is impossible to determine exact figures for baseline conditions and, therefore, additionality. As such, the CCX protocol was "rules-based" rather than "outcome-based," meaning that ranchers had to comply with a certain performance standard rather than be subjected to an additionality test at the project level. To determine the number of offsets generated by a project, models predicted how much carbon was being sequestered based on the geographic location of the ranch. This lack of precision was a potential disadvantage when buyers of credits were comparing options, and other types of projects might have seemed more legitimate, e.g., those measured against the Gold Standard or the Voluntary Carbon Standard.

Second, the extensive nature of ranch landscapes presents a suite of spatial challenges for verifying that management practices are in compliance with a given protocol. Like other carbon projects, all rangeland projects under the CCX protocol had to be reviewed by a third party. Ranches over 30,000 acres were field-verified; but of smaller ranches making up a pool of credits, only a random $10 \%$ of the acres were verified in the field. One rancher, explaining the geographic constraints associated with verifying range projects, gave an example of a verifier who attempted to apply methods used on farms in the Midwest to his topographically diverse 20,000 acre Montana ranch. Sending a verifier out into extremely rugged territory inhabited by grizzly bears and wolves was deemed a safety risk and, as such, the CCX protocol was changed so that a verifier only had to field check a small sample of sites on 30,000+ acre ranches for compliance. As the manager of one of these large ranches pointed out, however, this sampling approach had the potential to mischaracterize the amount of carbon being sequestered by the ranching property as a whole (sequestration rates vary across the ranch property), which could result in potential problems for the rancher seeking payment for credits supposedly generated.

\section{The Legitimacy Problem: Additionality Concerns When Ranchers Are Already in Compliance}

Another problem involves how to treat ranchers that already are in compliance with a given protocol before they enroll. For a carbon offset to be legitimate, there must be assurance that the carbon being removed from the atmosphere by the project is in addition to what would have been removed if there were no carbon payments. The ideal rangeland carbon sequestration project arguably would take place on a ranch where the soil was being poorly managed, and where the rancher could not afford to change practices even if he or she wanted to. In theory, the prepaid revenue from the sale of the carbon offsets generated by the ranch would pay for the transition to a more sustainable approach to rangeland management, one that increases vegetation, resulting in "real" additionality.

In reality, our research found that the only ranchers who participated in the CCX voluntary carbon market were ones who were already in compliance with the protocol, or who were transitioning (for other reasons) to management practices that would be in compliance with the protocol, with funding other than that promised by the offsets. This raises questions about the extent to which such projects provide additionality. One aggregator argued that these projects do provide additionality - that early actors in a carbon market should be included to prevent them from adopting unsustainable management practices or converting the land to development or cropland; essentially an "avoided degradation" argument. While forest owners can be paid for avoided deforestation and degradation under some protocols (e.g., the United Nations program to reduce emissions from deforestation and degradation, REDD) ${ }^{\mathrm{iii}}$ if they can prove that without carbon payments they would manage in a way that reduces forest carbon sequestration, there currently is no such protocol for rangelands. This probably is due to the fact that opinions differ regarding the imminence of the rangeland conversion threat, and the legitimacy of an avoided conversion offset. One study, however, found that conversion rates in the prairie potholes region of the United States exceed tropical rainforest conversion rates. ${ }^{4}$

Although an argument could be made for excluding precompliant ranchers from participating in carbon markets in order to maintain legitimacy in the marketplace, there are a number of implications associated with such a strict definition that policymakers will need to consider. First, if these ranchers - often the opinion leaders in their communitiesare excluded, it could be harder to engage the more mainstream ranchers who look to the good stewards and innovators in their communities for guidance. Second, there is an argument for "stewardship equity"; that ranchers who have been practicing carbon-friendly management for a long time should be rewarded, versus only rewarding ranchers who have come to it recently. Third, there is a strong belief among some ranching and conservation groups that paying ranchers for keeping carbon sequestered (the avoided conversion or degradation argument) is valid in the carbon world, especially given current development and land conversion threats to rangelands in the western United States in particular. Fourth, rangeland carbon protocols call for sustainable range management practices that have environmental benefits

\footnotetext{
iii For more information on the United Nations Collaborative Programme on Reducing Emissions from Deforestation and Degradation (REDD), see Web site www.un-redd.org.
} 
beyond carbon sequestration, and are therefore worth rewarding through economic incentives.

\section{Barriers to Engaging Ranchers}

In fall 2009 there were approximately 1,000 ranchers enrolled in CCX, representing about 5 million acres of rangeland concentrated primarily in South Dakota, North Dakota, Nebraska, and Montana. It is no coincidence that those are the regions where the two biggest aggregators work - the National Carbon Offset Coalition (located in Butte, MT) and the North Dakota Farmers Union. The primary way ranchers engaged in the voluntary carbon market was if an aggregator contacted them directly or they attended a presentation by one of the aggregators and decided to enroll. There clearly is a need for more effective outreach mechanisms to help ranchers participate in market-based opportunities. Most ranchers we spoke with indicated that the Natural Resource Conservation Service (NRCS) would be the logical governmental entity to implement a rangeland carbon offset program (with the help of Technical Service Providers). Others suggested that local Resource Conservation and Development Coordinators and/or local nonprofit conservation organizations could be effective intermediaries as well.

In addition to lack of awareness about opportunities, many ranchers have concerns about the role of the federal government in voluntary or compliance carbon markets, raising questions about which agency should be responsible for regulating a carbon offset program. Most ranchers interviewed indicated that they would be more hesitant to participate in a compliance carbon market if it was regulated by the Environmental Protection Agency (EPA) due to the widespread perception that the EPA is not as knowledgeable about the realities of range management, especially when compared to more familiar agencies like the NRCS. A significant challenge for the creators of future market institutions will be overcoming the suspicion of and antipathy toward government that many ranchers feel.

Other barriers to rancher participation in a carbon market include financial, technical, and psychological issues associated with transitioning to more sustainable and presumably carbon-friendly range management practices. The low price of carbon credits on the CCX ${ }^{\mathrm{iv}}$ in 2009-2010 made it financially improbable if not impossible for landowners to undertake the costs associated with documenting, registering, and verifying their credits. The majority of landowners interviewed for this project already had invested in both the infrastructure and documentation necessary to qualify for CCX registration through cost-sharing programs such as the US Department of Agriculture's Environmental Quality Incentives Program and with grazing plans that had been drawn up with the assistance of local NRCS staff. Also, none of the three aggregators enrolling landowners included

\footnotetext{
iv In mid-2010, the price of one carbon credit or $1 \mathrm{mtCO}_{2}$ was being offered for $\$ 0.10$-less than the $\$ 0.15$ per credit fee that CCX charges to landowners to register their credits for sale.
}

in this study charged up-front for their services; rather, they took their fees as commission once credits were sold. One landowner commented that when the CCX trading price was hovering at $\$ 0.40 /$ ton, the sale of credits would not have even covered his costs for enrolling. It is unclear at what price carbon sequestration becomes a financially viable and attractive mechanism for incentivizing landowners to switch to more carbon-friendly management.

Another set of challenges has to do with the technical aspects of changing a grazing system on a ranch. One rancher, for example, referred to the difficulty in changing the ingrained behavior of cows from continuous to rotational grazing (required at one point by the CCX protocol). She emphasized how essential it was to have monetary and technical assistance as well as moral support and coaching throughout the process because of how complex and lengthy the transition can be (see Trigg Ranch case study, this issue). One consultant with whom this rancher worked told her that if she could complete the transition to a managed grazing system involving rotational grazing over a 10 -year period, that would be considered a success. Good institutional design thus will need to ensure that there is a strong support system in place to assist and encourage ranchers in a transition to range management practices that precipitate the reversal of soil degradation and increased plant growth.

Finally, a number of ranchers felt that the process of enrolling land and selling credits on the CCX was obscure. A common experience involved an aggregator contacting the rancher unsolicited, directing him/her to the required documentation to submit, and instructing him/her to wait for payment. We found that many ranchers would have liked to have better understood what was happening vis-à-vis the credits they were generating, and how they were being sold. One aggregator equated carbon offsets with any other traditional commodity, suggesting that allowing landowners to act as owners of shares in an equity market and hold or sell their credits at any time would give them a better sense of control. Some ranchers expressed concern over equity and fairness issues, suspicious that "someone's getting rich off of [them]." Transparency thus is an important component of market credibility and viability and will need to be addressed in any voluntary or compliance market.

\section{Implications for Policy and Outreach}

As markets for environmental services other than carbon sequestration (e.g., water quality, biodiversity) in both the United States and internationally gain traction as potentially significant tools for conservation of natural resources, the CCX rangeland carbon experience yields two important lessons. The first is the importance of developing and implementing quantification tools and protocols that are credible and transparent. The CCX rangeland protocol's use of admittedly imprecise methodologies to quantify carbon sequestration and the lack of standards around additionality requirements likely contributed to concerns about credit quality and to the 
continually lower and lower prices of carbon credits. Project eligibility, assurances about additionality, and credible performance and verification standards will be essential components of robust environmental markets.

The second is the importance of understanding and defining the role of private landowners in the marketplace. These actors will be major suppliers of ecosystem services to the market, and creating an interface that is straightforward, transparent, and with affordable transaction costs will be essential to engaging them in this venture. The failure of the CCX has left a number of ranch owners with worthless carbon credits and likely skepticism of the idea of environmental markets as a viable income stream to incentivize or subsidize conservation activities.

Given these lessons and the set of opportunities and challenges outlined above, policymakers will have a number of important decisions to make as they oversee the development of institutions aimed at incentivizing carbon-friendly range management. Considerations include the following. First, investing in research aimed at developing more practical methods for quantifying soil carbon could enhance the credibility and legitimacy of a future carbon market and avoid the "junk carbon" problem.

Second, in the absence of technology that would allow for project-based additionality tests, deciding how to define additionality for rangeland carbon projects and, closely related to that, how to treat ranchers already in compliance with a given protocol, will be an important policy consideration. One possibility is that early actors could be allowed to participate via a mechanism similar to REDD (for ranchers it might be "REED"-Reducing Emissions from Erosion and Rangeland Degradation) but they would need to provide proof of a threat of conversion to a different use. Researchers at Colorado State University currently are developing models aimed at quantifying this threat in different geographic contexts. Another way to address the challenges associated with including innovators in a market would be to develop a hybrid system involving both the government and the market that would compensate ranchers for carbon-friendly range management and perhaps better satisfy the demand for legitimacy in the market. The marketplace could be restricted to ranchers who can prove additionality more strictly defined; whereas ranchers already practicing sustainable and carbon-friendly management could participate in conservation incentive programs that provide government payments for good stewardship.

Third, a robust, comprehensive support system for ranchers seeking to make a transition to more sustainable, carbonfriendly range management practices is badly needed. This type of support system would need to address financial, technical, and psychological aspects of the transition to reduce transaction costs and minimize trade-offs. The effectiveness of this support system likely would depend on the capacity of the intermediaries that work with ranchers, be they government agencies such as the NRCS, or local nonprofit organizations, or the aggregators seeking to enroll them in offset programs. Intermediaries will need to employ outreach strategies that, among other things, proactively address misconceptions about how participating in the carbon market might affect landowners' private property rights.

In sum, we found a cautious optimism among ranchers about the potential to be compensated for the carbon sequestration that ranches can provide; but it will be important for researchers, policymakers, and market developers to invest significant time and energy into better understanding the physical and human geography of ranch landscapes. We suggest that ranchers who would like to transition, but need help, are the ones whose experiences should inform the design of institutions aimed at incentivizing and assisting that transition to sustainability. Conducting a series of focus groups around the West that include diverse groups of ranchers could garner better insights into the realities of transitioning to different grazing systems, and the types of trade-offs that will come with different institutional design strategies.

\section{Acknowledgments}

The authors would like to acknowledge the ranchers who provided us with their time and insights, as well as the Rangelands reviewers and editors who provided detailed suggestions for improving this paper.

\section{References}

1. US Department of Agriculture, US Forest Service. 1989. An analysis of the land base situation in the U.S.: 1989-2040. Fort Collins, CO, USA: US Department of Agriculture, Forest Service, Rocky Mountain Forest and Range Experiment Station. Gen. Tech. Rep. RM-181. 76 p.

2. Mitchell, J. E. 2000. Rangeland resource trends in the United States: a technical document supporting the 2000 USDA Forest Service RPA Assessment. Fort Collins, CO, USA: US Department of Agriculture, Forest Service, Rocky Mountain Research Station. Gen. Tech. Rep. RMRS-GTR-68. 84 p.

3. [CCX] Chicago Climate Exchange. 2009. Agricultural best management practices-sustainably managed rangeland soil carbon sequestration offset project protocol. Chicago, IL, USA: Chicago Climate Exchange. 70 p. Updated 20 August 2009.

4. Stephens, S. E., J. A. Walker, D. R. Blunck, A. Jayaraman, D. E. Naugle, J. K. Ringelman, and A. J. Smith. 2008. Predicting risk of habitat conversion in native temperate grasslands. Conservation Biology 22(5):1320-1330.

5. Diaz, D., S. Charnley, and H. Gosnell. 2009. Engaging western landowners in climate change mitigation: a guide to carbon-oriented forest and range management and carbon market opportunities. Portland, OR, USA: US Department of Agriculture, Forest Service, Pacific Northwest Research Station. Gen. Tech. Rep. PNW-GTR-801. 81 p.

Authors are Associate Professor, gosnellh@geo.oregonstate.edu (Gosnell) and Research Assistant (Robinson-Maness), Dept of Geosciences, Oregon State University, Corvallis, OR 973315506, USA; and Research Social Scientist, USDA Forest Service, Pacific Northwest Research Station, Portland, OR 97205, USA (Charnley). This study was funded by the USDA Forest Service. 